\title{
Ground Magnetic Investigation of Subsurface Structures Affecting Wadi Thuwal Area, KSA
}

\author{
Mansour A. Al-Garni and Mohamed M. Gobashy \\ Dept. of Geophysics, Faculty of Earth Sciences, \\ King Abdulaziz University. Jeddah, Saudi Arabia \\ maalgarni@kau.edu.sa
}

Received: 25/10/2009

Accepted: 20/1/2010

\begin{abstract}
Ground magnetic survey was carried out in Wadi Thuwal area, north of Jeddah, during winter and spring of 2007-2009. The survey was intended to delineate the subsurface structures and covered an area of about $130 \mathrm{~km}^{2}$, located between latitudes $22^{\circ} 10^{\prime} 00^{\prime \prime} \mathrm{N}$ and $22^{\circ} 16^{\prime} 53.5^{\prime \prime} \mathrm{N}$ and longitudes $39^{\circ} 06^{\prime} 40^{\prime \prime} \mathrm{E}$ and $39^{\circ} 16^{\prime} 20^{\prime \prime} \mathrm{E}$. The survey was conducted along profiles taking EW and NS directions. The field data were reduced and then interpolated to produce a high resolution total intensity ground magnetic map (HRTMI). Shaded relief maps have been effective in showing structural trends and characteristic anomaly patterns. Magnetic susceptibility measurements (k) were attended throughout the entire ground survey. The depth to the sources of the ground-magnetic anomalies was estimated using 2D and 3D Euler deconvolution. Observed surface faults are expected to be initiated from the basement. 2D and 3D analytic signal analysis and derivative maps show several trends crossing the study area. These trends, which are attributed to faults or contacts, are extended to the east of the study area, and further to the Arabian Shield (East), where some of them represent major faults that evidently have an impact on the water distribution potentiality of the Wadi. These trends are basically taking NE-SW faults direction, the rift shoulder master faults with N-S direction, NW-SE, and NNE-SSW normal faults direction. The Euler deconvolution analysis using $\mathrm{N}=1$, reveals distinctive patterns of subsurface dikes. These may be attributed to dike swarms trending NW-SE and NNW-SSE.
\end{abstract}

Keyword: Magnetic, Thuwal, 3D Euler deconvolution, analytic signal. 


\section{Introduction}

A high resolution ground magnetic survey was performed in Wadi Thuwal area, north of Jeddah, surrounded by Harrat Thuwal to the east, Red sea coastal plain to the west, city of Thuwal to the north and Dahaban to the south. This area lies between latitudes $22^{\circ} 10^{\prime} 00^{\prime \prime} \mathrm{N}$ and $22^{\circ} 16^{\prime} 53.5^{\prime \prime} \mathrm{N}$ and longitudes $39^{\circ} 06^{\prime} 40^{\prime \prime} \mathrm{E}$ and $39^{\circ} 16^{\prime} 20^{\prime \prime} \mathrm{E}$ (Fig. 1). Generally, this magnetic detailed survey along with the geological field observations is considered as the first survey of this level in Wadi Thuwal. The main target of the survey was to identify and delineate qualitatively the basement rock structures, their distribution and trends, in the study area.

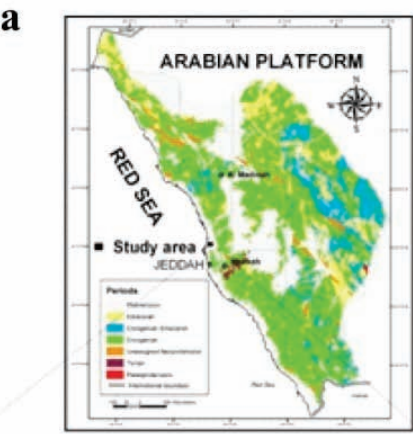

b

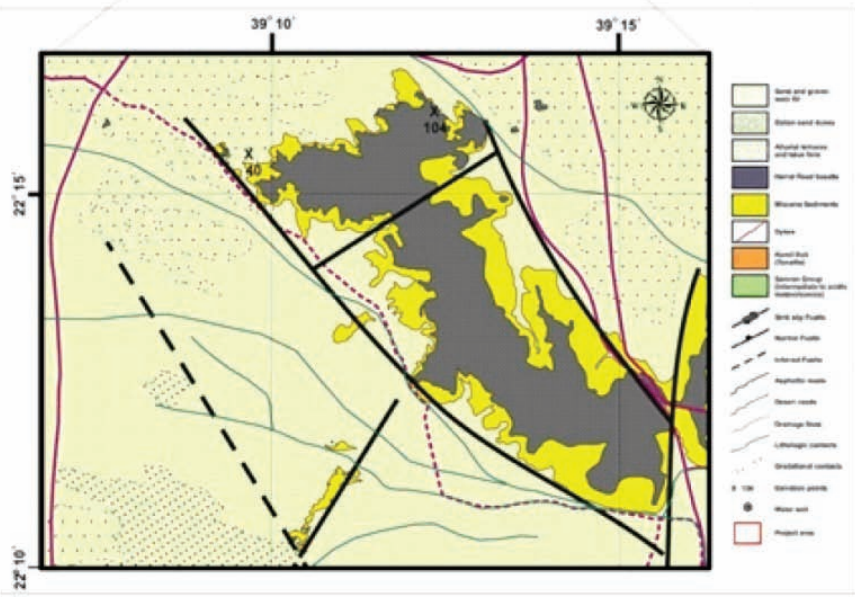

Fig. 1. Location map of the study area (a), and the detailed geologic map (b) (Al-Garni et al., 2009). 


\section{Geologic Setting}

The study area lies to the west of the Arabian Shield of Saudi Arabia and constitutes a part of the Red Sea coast (Fig. 1a). It is largely covered with wadi deposits that represent about $70 \%$ of the total surface area. Rock exposures of Oligocene-Miocene sediments and Quaternary volcanics are cropping out in the northeastern part of the study area.

The western part of this area is represented by a wide coastal plain covering most of it and a basalt plateau occupying its northeastern part. The coastal plain is almost flat with a general gentle northwest slope. The average elevation along the plain is about $45 \mathrm{~m}$ at the extreme southeast, $10-15 \mathrm{~m}$ at the west and southwest, and $4-5 \mathrm{~m}$ above sea level at the extreme northwest. It is traversed by a simple system of drainage lines that mostly fade out in the central part of the area. The main channel runs through the area from the southeast (the upstream) to the northwest (downstream) close to the basalt plateau (Fig. 1b).

The Harrat basalt plateau, high magnetic zone, is a fault controlled mass extending along NW-SE direction. The elevation of the upper surface of the plateau ranges between $75 \mathrm{~m}$ at its northwestern part and about $100 \mathrm{~m}$ at the southeast.

Based on the field investigations (Al-Garni et al., 2009), the description of the main rock units, exposed in the mapped sector, is summarized as:

\section{I- The Precambrian Crystalline Basement Rocks}

These rocks are exposed at the extreme eastern and central parts of the area (Fig. 1b). They are represented by three major rock units; namely: Samran Group (the oldest), Kamil Suit, and younger dykes. The terminology of the rock units is after Ramsay, (1986). The basement exposures are limited at the western margin of the area by a N-S to NNW-SSE regional rift shoulder fault related to the Red Sea tectonics and are traversed by major strike slip faults of ENE-WSW trends. The younger dykes, on the other hand, are disrupted by two intensive dyke swarms along NE-SW and NNW-SSE trends. The former is mainly acidic to intermediate in composition; while the latter is generally represented by intermediate and basic varieties. The NNW-SSE dyke swarm is most probably of Tertiary age and related to the Red Sea tectonics. 


\section{II- The Cenozoic Sedimentary and Volcanic Rocks}

The Cenozoic rocks are represented by the Oligocene-Miocene sediments (Shumaysi Formation), the Quaternary Basalt (Harrat Khulaysiyah), and the Holocene Wadi deposits. The main exposures of the former two units constitute plateau landforms in the northern and southern parts of the mapped area (Fig. 1b). They lie along fault contacts against the basement rocks and their distribution in the other parts of the area is largely controlled by normal faulting.

The basement exposures in the eastern part of the mapped sector are controlled by a major rift shoulder fault related to the Red Sea tectonics trending N-S to NNW-SSE, and by a major set of strike-slip faults of a NE-SW direction. They are also traversed by major NE-SW dyke swarm in which individual dyke may extend for several kilometers along strike. These structural features are expected to play a considerable role in the basement configuration under the Holocene wadi deposits of the coastal plain.

\section{Magnetic Survey}

The ground magnetic survey of Wadi Thuwal covers an area of about $13 \times 10 \mathrm{~km}^{2}$. Two units of portable GEM 19T proton precession magnetometer were used, one unit to measure the total magnetic intensity field along the profiles and the other was used as a base station to record the diurnal variations of the earth magnetic field every 120 second. The survey was conducted along 36 profiles, 26 profiles were taking the E-W direction and the other 10, the N-S direction. The survey was conducted in two years (2007-2009), where the end of the field work of the first year, ended on Jan. $24^{\text {th }}$. The inter-profile spacing was taken between 1000 and $1300 \mathrm{~m}$. The inter-stations separation was between 30 and $50 \mathrm{~m}$ along the conducted traverses (profiles P1 through P13). A closer station separation was sometimes selected in order to obtain better anomalies definition. In the second year, the rest of the planned survey were conducted and ended on February, 2009. The same inter-profile spacing was used, between 1000 and $1300 \mathrm{~m}$, in average (in some localities) the spacing was $250 \mathrm{~m}$ and the inter-stations separation was between 30 and $50 \mathrm{~m}$ like before along the conducted traverses (E-W lines). For the South-North lines, the station spacing was fixed to 100 meters. The survey lines are posted on a satellite image map for Thuwal 
area (Fig. 2). The magnetic field data were corrected for daily variations using a specially designed Matlab package. All types of artificial noise are removed to ensure high quality data. The International Geomagnetic Reference Field (IGRF) (Tenth generation) was further removed to obtain a high resolution total intensity magnetic anomaly map.

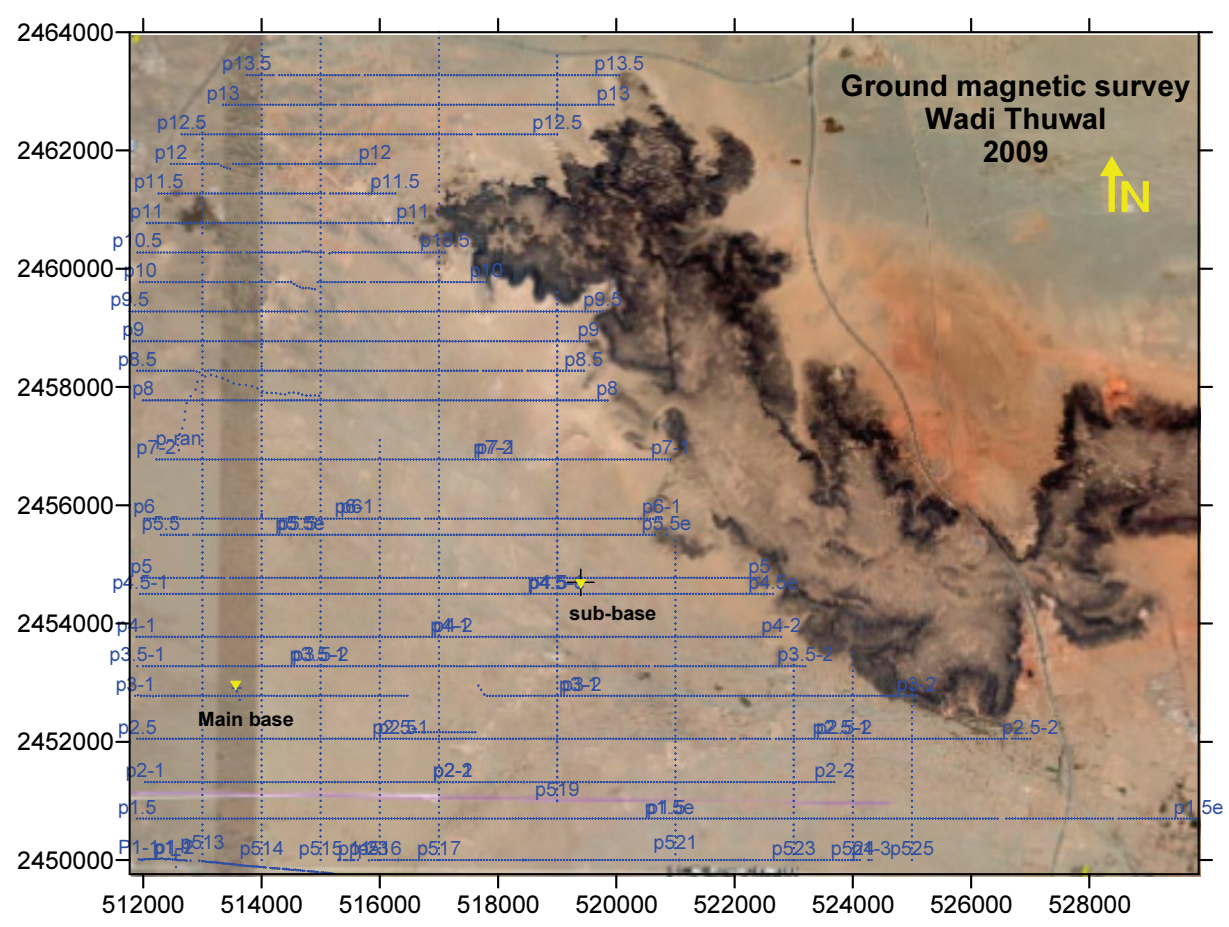

Fig. 2. Detailed locations of the complete set of the conducted magnetic traverses.

\section{Total Magnetic Intensity Anomaly Map}

The total magnetic intensity (TMI) anomaly map of Wadi Thuwal as compiled from the complete set of profiles (36), is shown in Fig. 3. The map emphasizes the intensity and the wave lengths of local anomalies. Several anomalies can be referred to distinct magnetic zones.

Two main features are observed; low, and relatively high frequency zones represented by anomalies $\mathbf{A}, \mathbf{B}$, and $\mathbf{C}$. These anomalies are generally trending NE-SW, perpendicular to the Red Sea trend (NW-SE), attaining magnetic amplitudes which vary from -50 to $0 \mathrm{nT}$. On the other hand, the High magnetic anomalies (zones D, E, F, and $\mathbf{G}$ ) are 
characterized by relatively flat magnetic signatures, representing different trends NS, NW-SE, E-W and NW-SE, NE-SW, respectively. A relatively quite magnetic (zone $\mathbf{H}$ ), showing between latitudes 2450000 and $2454000 \mathrm{~N}$ and longitudes 51900 and $523500 \mathrm{E}$, may be attributed to relatively deep-seated low relief basement structures.

Based on the above classification, tentative trends may be posted on the map to reveal structures/and or lithologies that represent the cause of such anomalies. Figure 4 shows the possible three major trends as obtained from such analysis:

1. The NE-SW, and NNE-SSW trends are indicated by F1, F2, F3, and $\mathrm{F} 4$, and some other minor lineaments.

2. The NW-SE trend is indicated by F5, F6, F7, F8 and other minor trend as shown on the map.

3. The N-S trend is represented by F9, F10, F11, F12.

4. An evidence of shearing may be observed close to Harat Thuwal and this is indicated by symbol SH.

5. The rose diagram in the sub-panel reflects clearly these directions. Moreover, several minor magnetic trends are observed even though they have low frequency on the map.

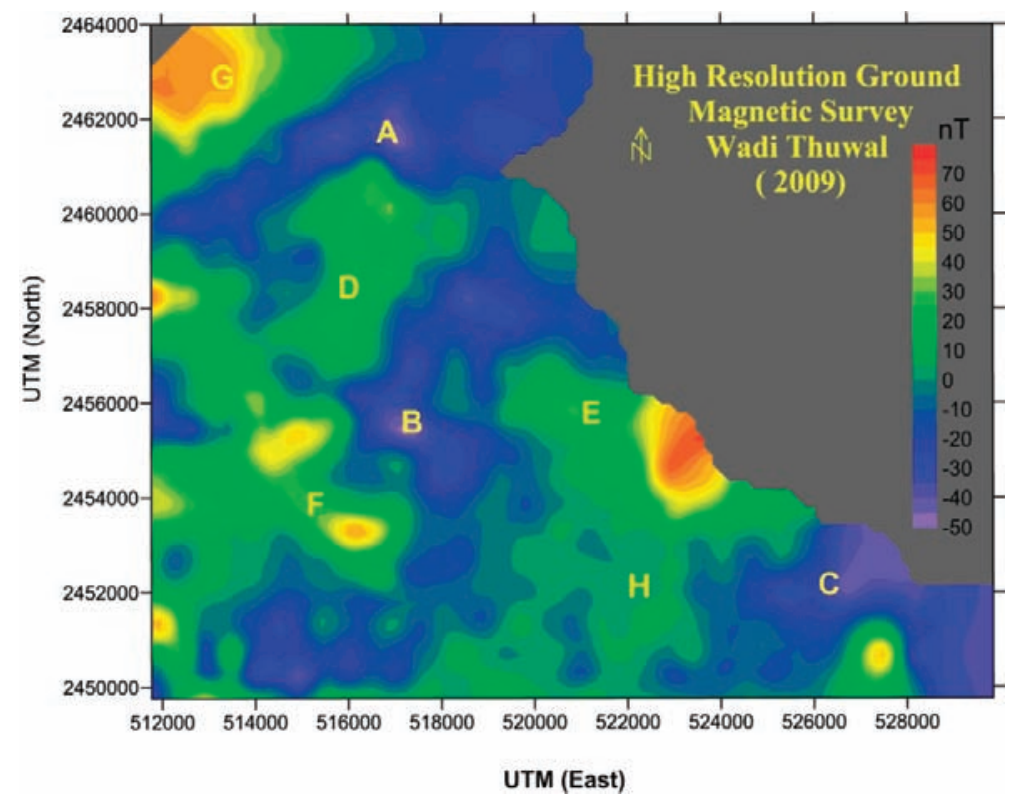

Fig. 3. High resolution ground total magnetic intensity map (HRTMI), Wadi Thuwal. 


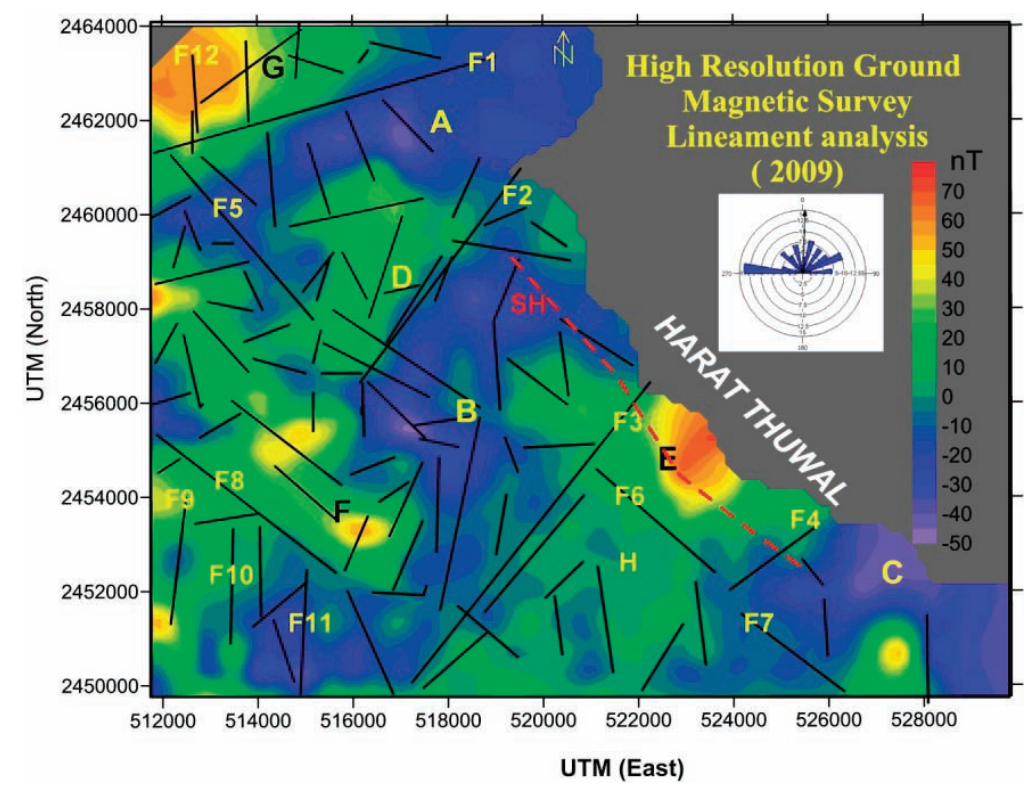

Fig. 4. Possible magnetic lineaments as interpreted and posted on the TMI map of Wadi Thuwal.

\section{Magnetic Susceptibility of the Rocks}

Volume corrected apparent magnetic susceptibility readings were determined for 2496 rock outcrops or hand samples, taking from the study area (Fig. 5). Magnetic susceptibility readings of all rock samples were measured using a Geophysica KT- 6 susceptibility meter in the field and in the lab. The instrument is accurate to $1 \times 10^{-5} \mathrm{SI}$ units, and all measurements were converted from SI to cgs units. Each magnetic susceptibility value in this paper represents an average of multiple readings. The Geophysica KT-6 calculates the volume susceptibility by assuming the sample shape as an infinite half space.

Magnetic susceptibility depends largely on a rock's magnetic mineral content. Mafic rocks generally have higher magnetic susceptibilities than felsic rocks because mafic rocks are typically more abundant in strongly magnetic minerals such as magnetite (Carmichael, 1982).

The highest average magnetic susceptibilities reveal the mafic rocks (Harrat Thuwal basalts) whereas the lowest average magnetic susceptibilities indicate the sedimentary and the felsic rocks. Mafic 
extrusive rocks have an average magnetic susceptibilities range of $0.96 \mathrm{x}$ $10^{-3}$ to $1.01 \times 10^{-3} \mathrm{cgs}$, carbonate and clastic rocks (located in some localities in the study area) have average magnetic susceptibilities range of $0.01 \times 10^{-3}$ to $0.14 \times 10^{-3} \mathrm{cgs}$, respectively, and most of the Quaternary sedimentary cover and wadi fills have average magnetic susceptibilities range of $0.14 \times 10^{-3}$ to $0.82 \times 10^{-3} \mathrm{cgs}$.

Simple statistics were calculated for the magnetic susceptibility of rocks from the study area. Their mean magnetic susceptibility value is $0.297 \times 10^{-3} \mathrm{cgs}$ and the standard deviation is $0.1085 \times 10^{-3} \mathrm{cgs}$. A histogram of susceptibility values (Fig. 6) shows that the majority of susceptibility values (about $40.3 \%$ ) are between $0.2 \times 10^{-3}$ and $0.3 \times 10^{-3}$ cgs, $26.2 \%$ are between $0.3 \times 10^{-3}$ and $0.4 \times 10^{-3}, 16.1 \%$ of the data are between $0.1 \times 10^{-3}$ and $0.2 \times 10^{-3} \mathrm{cgs}, 11.3 \%$ of the data are between 0.4 $\times 10^{-3}$ and $0.5 \times 10^{-3} \mathrm{cgs}$, about $3 \%$ of the data are between $0.5 \times 10^{-3}$ and $0.6 \times 10^{-3}$, about $1.2 \%$ of the data is located between $0.6 \times 10^{-3}$ and $0.7 \times$ $10^{-3} \mathrm{cgs}, 1.16 \%$ of the data are between zero and $0.1 \times 10^{-3} \mathrm{cgs}$, and finally $0.1 \%$ of the data are between $0.7 \times 10^{-3}$ and $0.8 \times 10^{-3} \mathrm{cgs}$.

The average surface horizontal rate of change of susceptibilities (Fig. 7), calculated using Robert's raw detector $3 \times 3$ filter) ranges between 0.0 and $0.05 \times 10^{-3} \mathrm{cgs}$ unit $/ \mathrm{m}$ i.e. the distribution of magnetic susceptibility is relatively homogeneous in the Wadi except close to the Harrat. However, minor variations are observed close to the south, trending North 35 East. Detailed sedimentological studies are also required to correlate between the magnetic susceptibility and rock types through the box and whisker plots. The above mentioned results show that the basaltic rocks (Mafic extrusive) in the Wadi are very rare (only dominant close to the Harrat) and play a minor role on the magnetic signature (i.e on the surface). Moreover, the other rock types have lower values of magnetization (carbonates and wadi fills) and their input in the magnetic signature is negligible. This was confirmed from the visual inspection and comparison between the total intensity map (Fig. 2) and the susceptibility distribution map (Fig. 5). A minor correlation exists between the patterns (highs and lows). In conclusion we may tentatively assume that most of the observed magnetic signature, reflects the effect of deep basement and/or basaltic materials underlying the sedimentary cover. Hence, we expect that the magnetic map reflects directly the effect of the basement topography in the study area. These magnetic 
susceptibilities can be used as an equality and inequality constraints for further inversion of the magnetic data.

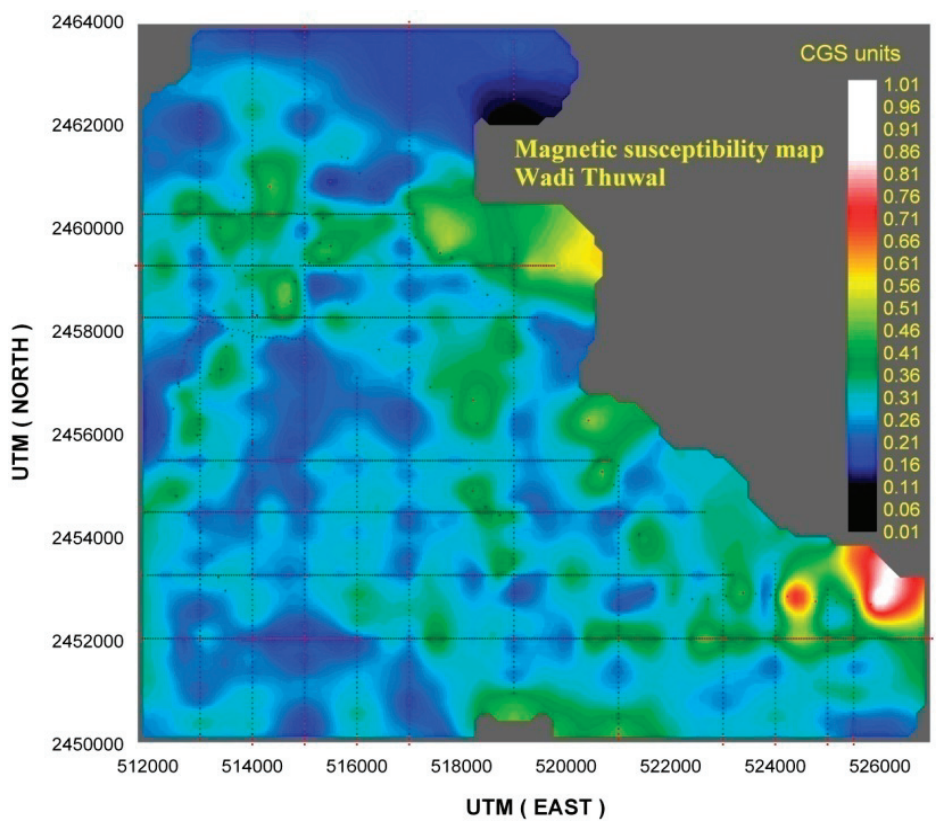

Fig. 5. Surface magnetic susceptibility map of the study area in cgs units. Red symbols indicate the measurement locations.

\begin{tabular}{|l|l|}
\hline First input row & 1 \\
\hline Last input row & 2496 \\
\hline Number of values & 2496 \\
\hline Number of missing values & 0 \\
\hline Sum & 741.573 \\
\hline Minimum & 0.051 \\
\hline Maximum & 1.011 \\
\hline Range & 0.959 \\
\hline Mean & 0.297 \\
\hline Standard deviation & 0.1085 \\
\hline
\end{tabular}

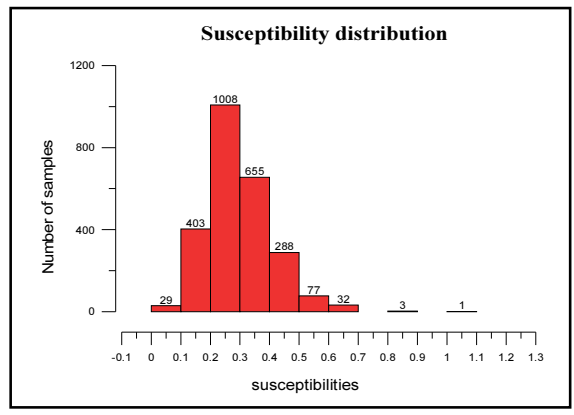

Fig. 6. Statistics and histogram showing the distribution of measured magnetic susceptibilities in the study area. 


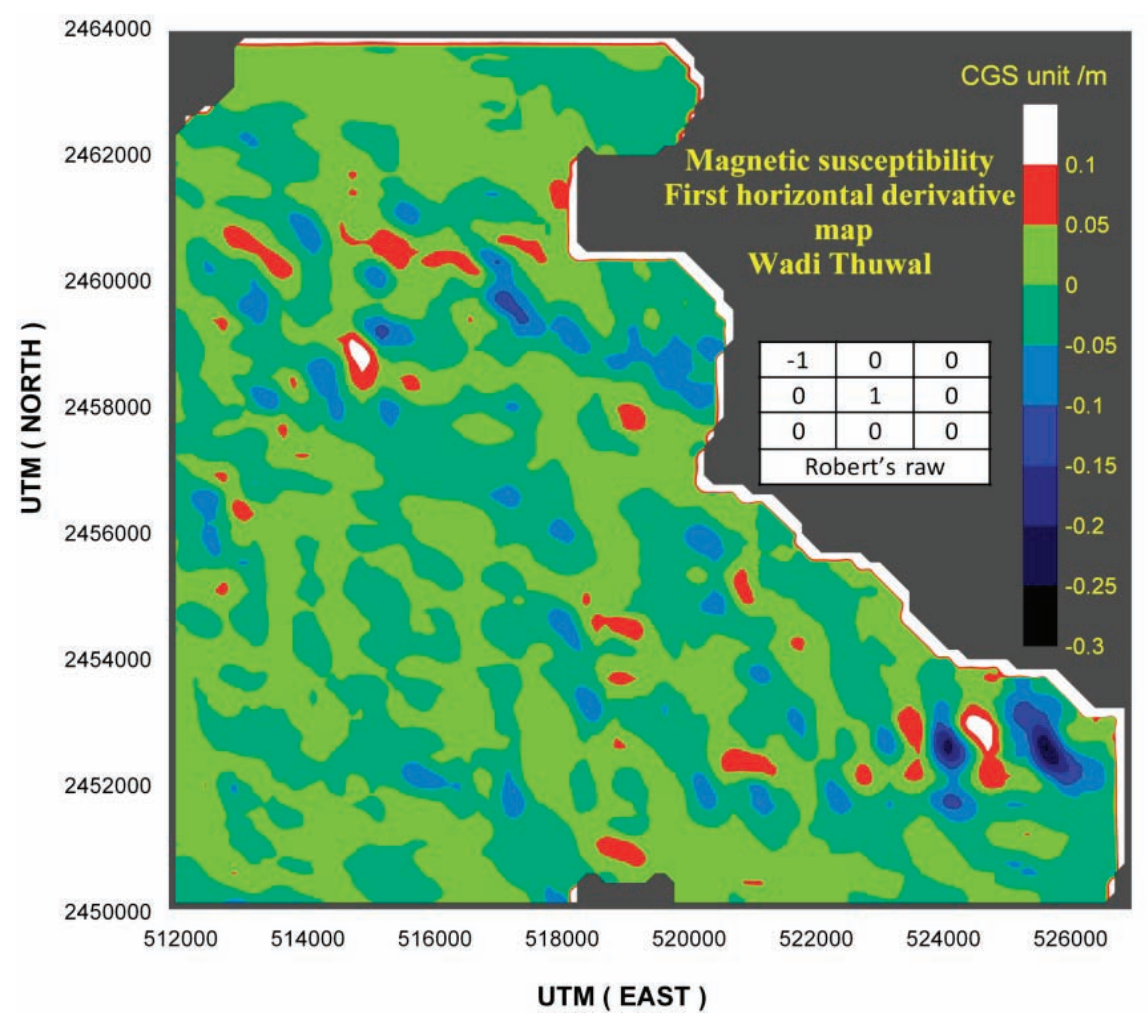

Fig. 7. First horizontal derivative map for the magnetic susceptibility of Wadi Thuwal area in cgs units/meter. The lower sub-panel shows the filter used.

\section{Shaded Relief Maps}

The shaded relief representations, treating the potential field data as a topographic surface, are most effective in the evaluation of magnetic anomaly maps. This is done because the vertical anomaly gradients are controlled by the depth to the causative structures. The 3D images enhance the features which trend roughly perpendicular to the direction of illumination and highlight geological trends, relating to the magnetization contrasts of the upper crust and to the depth of magnetic basement. This effect can be used to locate structurally significant lineaments, which are often not apparent on standard contour maps. Shaded relief images of the study area were generated to represent the residual magnetic data. We calculated the shaded reliefs at: a) $-43,47$; b) 51,43 ; c) 142,36 ; and d) $-140,39$, degrees with the light-source for declination and inclinations, respectively, (Fig. 8a , b , c , d). Northwest- 
strike features (red dashed lines) are clearly shown with the light source at 51, 43 and -140, 39 degrees, while northeast-strike features are clearly shown with the light source at 142, 36 and $-43,47$ degrees. The dominant feature is in the NE-SW direction, showing on panel $\mathbf{c}$ and a corresponding to anomaly $\mathbf{A}$ in Fig. 3. This may represent a major fault zone crossing the area and probably extending to the Arabian shield (basement). A second feature is in the NNE-SSW direction, which may be corresponding to anomaly B (Fig. 3). However, the lineaments which were attained from these directions (NNE-SSW) are less dominant than those previously mentioned and are partially observed in panels $\mathbf{b}$ and $\mathbf{d}$ (blue trends). The Red-Sea trend (NW-SE) is clearly presented using the light source at panel b $(51,43)$ and panel d $(-140,39)$. An interesting roughly circular feature is clearly evident in panel d. This may be explained as some granitic plutons in the basement. A number of minor $\mathrm{E}-\mathrm{W}, \mathrm{N}-\mathrm{S}$ trends are also shown in the four maps.
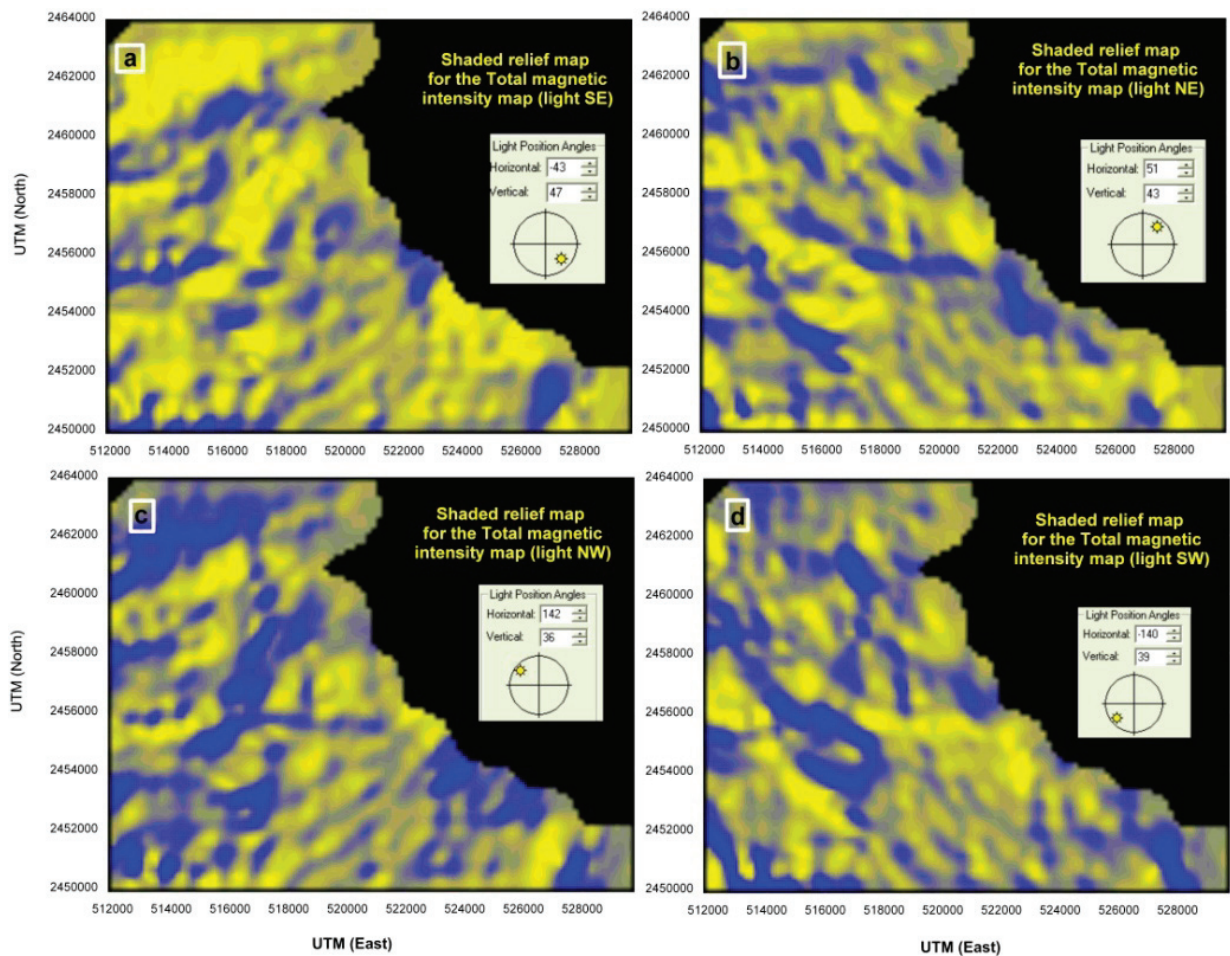

Fig. 8. Shaded-relief map for the total intensity map of Wadi Thuwal in (Fig. 3). Different declinations and inclinations are used. 


\section{D Cross Sectional Analysis of the Measured Traverses for Edge Recognition, and Depth Estimation}

Generally, magnetic data are interpreted to estimate the depths of the source rocks and their locations (Vacquier et al., 1951). Spector \& Grant (1970) addressed the depth estimation using the slope of power spectral density in statistical sense. Cordell \& Grauch (1985) calculated the horizontal gradient of the pseudogravity for boundary location, which peaks over a vertical contact; however, the peaks are somewhat offset for dipping contacts. Nabighian (1972, 1974 and 1984) showed that the total gradient or analytical signal peaks directly over arbitrary dip contact but is somewhat noisy estimator (Hansen et al., 1987). The width of the peak is used to estimate the depth to the causative source.

Numerous automatic processing methods join source location and depth estimation (Thompson, 1982). Werner deconvolution method fits elementary models to successive segments of a profile and successfully estimates source location, depth and dip (Hartman et al., 1971, and Jain, 1976). Naudy (1971) used a similar approach employing prism and thin plate models. Solving for the causative body positions and obtaining an indication of causative body type were described by Thompson (1982), who provided a method which utilized Euler's equation to successive segments of a pole-reduced profile. Reid et al. (1990) described a fast means of processing magnetic data to drive trends and depth estimation using an automatic or semiautomatic algorithm.

To analyze the measured traverses in our study quantitatively, we calculated for each traverse the gradients (horizontal and vertical) and then calculated both the 2D Analytic Signal (AS) and 2D-Euler deconvolution using homogeneity equation to estimate the locations of magnetic dip contacts (possible faults), dikes, and depth to the magnetic sources.

\section{Euler Deconvolution Technique for Dike Detection}

Euler deconvolution is commonly employed in magnetic interpretation because it requires only a little prior knowledge about the magnetic source geometry, and more importantly, it requires no information about the magnetization vector (Thompson, 1982, Reid et al. 1990, and Gobashy \& Al-Garni 2008). Therefore, it can be applied to 
areas where the geology is poorly known or in wadies where the alluvial deposits hide the subsurface magnetic causative sources, which is the case in Wadi Thuwal.

Euler deconvolution was applied to profiles along $\mathrm{x}-\mathrm{z}$ profiles as in the case of $2 \mathrm{D}$ using structural index $\mathrm{N}=1$. Figure 9 is a sample plot of the 2D Euler deconvolution and analytic signal analysis for profile P1. An image of the subsurface magnetic sources distribution is presented (third panel) where all possible dikes, which have a subtle signature on the reduced-to-pole (RTP) and TMI maps, are drawn overlapping the clustered solutions resulted from Euler deconvolution. The gradients were used also to estimate and enhance solutions. The RTP profile was calculated for the total 36 profiles. Generally, the solution of Euler deconvolution show that the depths range between 250 to 500 meters and an overall average depth can be of about 390 to 450 meters. The shallow source depths most probably reflect basaltic lenses in the area and do not reflect the general basement surface or the extended faults from basement to the surface. No other sources of intra-sedimentary anomalies are considered based on the geological studies carried out in the area.

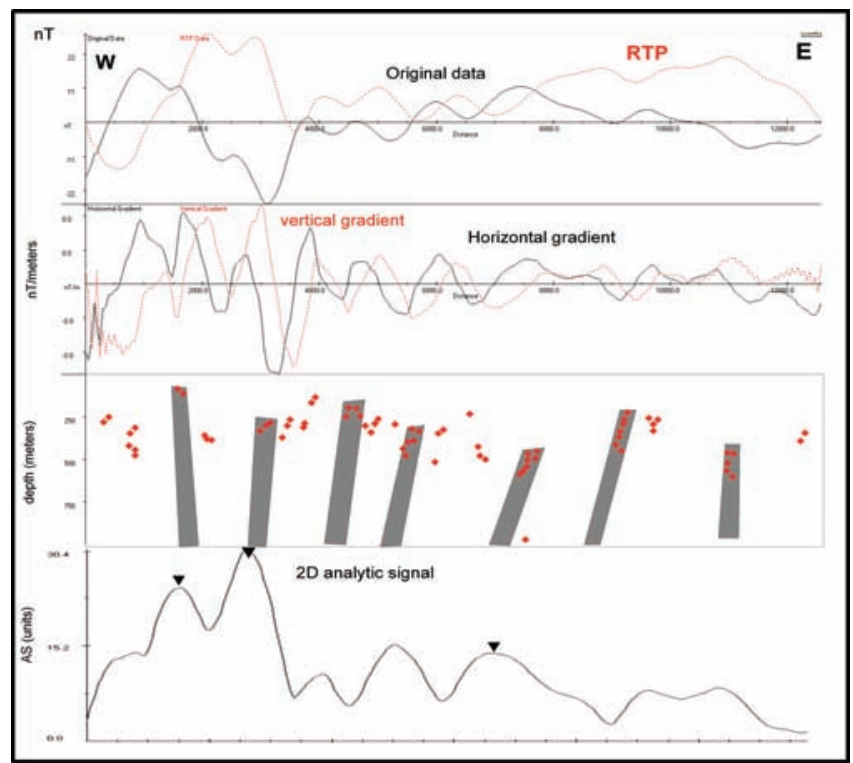

Fig. 9. Sample plot for the 2D Euler deconvolution and analytic signal analysis along profile p1, Thuwal area. 


\section{Analytic Signal for Edge Detection}

The analytic signal is a complex function that makes use of the Hilbert transform properties to detect geologic boundaries, faults and dykes. It has been shown that it is effective for the interpretation of subsurface magnetic contacts (e.g., Nabighian, 1972, 1974). This method does not require a prior knowledge of magnetization directions and thus does not require reduction-to-the-pole processing. A geologic contact or fault with significant susceptibility contrast can be detected by mapping the maxima of the simple analytic signal, which is composed of the two horizontal and one vertical gradient (Nabighian, 1972, 1974, 1984, Roest et al., 1992, and Gobashy \& Al-Garni 2008). It is typically assumed that the causative sources are near-vertical, step-like geologic structures (Hsu et al., 1996), in such a case the maxima are located directly over the edges of the structures. An interpretation pitfall of using this method is that two maxima from two nearby parallel edges get merged to give one maximum if the half-width between the edges is less than the depth (Atchuta Rao et al., 1981). For further derivation of the mathematics of the technique, the reader can be referred to Hsu et al., (1996). Consequently, a dike could be interpreted as a geologic fault or contact. This problem could be mitigated somewhat by acquiring the magnetic data close to or on the ground. This is the case in the present study where a high resolution ground magnetic (HRGM) survey was carried out.

The technique was applied to all the profiles and the maxima were determined (the analytic signal profile is shown in the lower panel of the sample plot in Fig. 9). The location of the maxima is plotted and posted on the magnetic intensity map (TMI) for all traverses and correlated with the geologic information to detect possible magnetic contacts in Wadi Thuwal area. To obtain a comprehensive spatial distribution of solutions, we plotted the stacked analysis of the Euler deconvolution solutions, using $\mathrm{N}=1$ (dike), and the analytic signal solutions for contacts or edges for the whole traverses and then overlapped on the TMI map (Fig. 10). Hence, the possible trends of these results are shown in Fig. 10. These analyses show a possible existence of a regime of dikes crossing the area (dike swarm) that runs NW-SE or NNW-SSE. Moreover, the analytic signal solutions, generally, show a correlation with the dike swarms as interpreted from the Euler solutions and hence the trends NW-SE, NNWSSE, and NE-SW were detected. 


\section{D Euler Deconvolution}

Conventional Euler deconvolution cannot estimate the depths along with the structural indices in the study area. In the conventional Euler deconvolution the depth estimation is based on the assumed structural index (SI); this is subjective and depends on the geological experience. In this section (3D analysis), the pilot technique, which were proposed by Stavrev (1997), Gerovska \& Bravo (2003), and Stavrev et al., (2003) was applied to interpret the ground magnetic anomalies of Wadi Thuwal area, assuming a linear background with un-prescribed structural index based on the properties of the differential similarity transformation (DST). We intended to calculate the depths and the structural indices that are associated with the different clusters, resulting from the different stages of the algorithm, and then use them to infer the relationships between the resulted lineation and the geologic units in the study area. The target is to presume the common structural elements in the area magnetically. The method may be summarized briefly as follows:

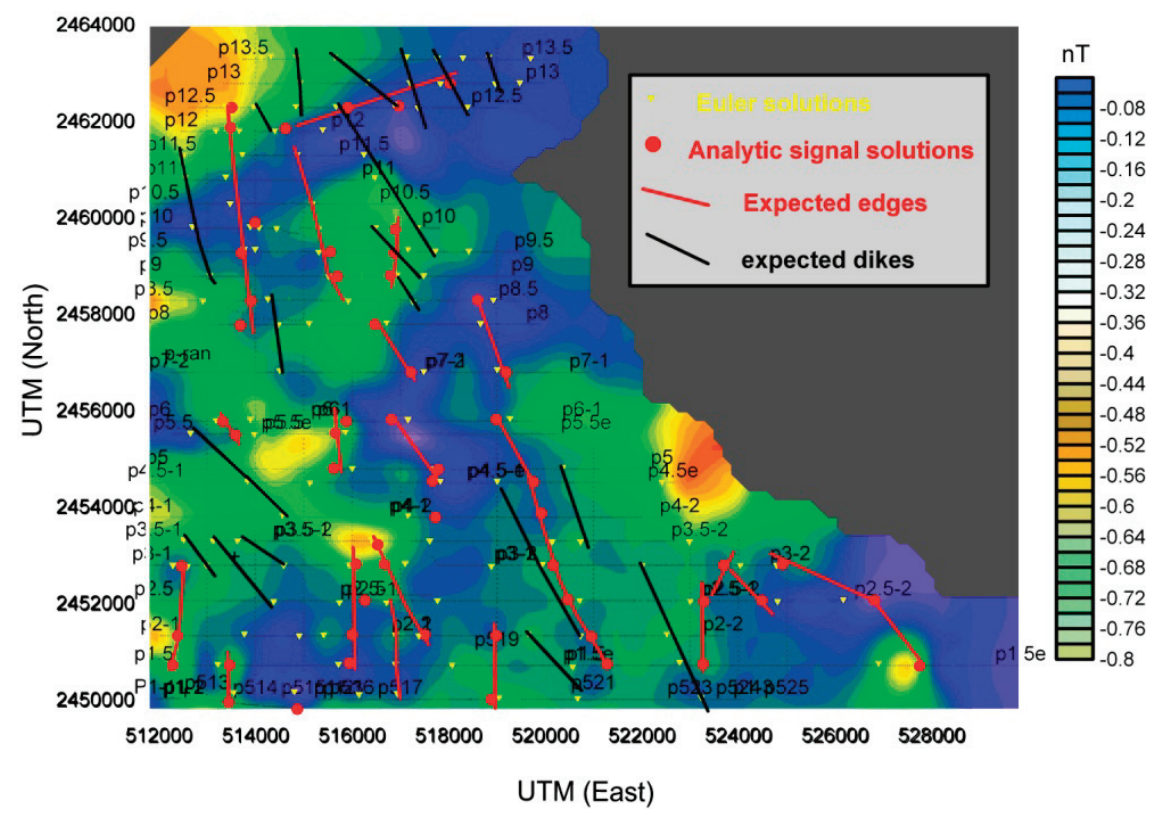

Fig. 10. Euler solutions for $\mathrm{N}=1$ (dikes), and analytic signal solutions (red circles) for contacts or edges. Possible trends of these results are posted and overlapped on the (TMI) map. 
The reduced rectangular grid is used for the present study. The necessary arguments and parameters for carrying out the deconvolution are (Gobashy, 2006; Al-Garni, 2007):

1. Acceptance Level $\tau$. It represents the maximum value allowed for the relative standard deviation (in relation to the estimated depth) weighted by the estimated structural index. This is taken as 0.05 and it is an empirical criterion as suggested by Thompson ( 1982). This value is compared to a threshold value, $\tau=0.0002$. Later this acceptance level is changed to be 0.009 for second cluster stage (as we shall explain later) to eliminate highly dispersed solutions.

2. $\rho_{\text {mic }}$, fraction of grid spacing parameter to be used in the microscale clustering. When multiplied by the grid spacing, it gave the maximum horizontal distance allowing two solutions to belong to the same cluster. $\rho_{\text {mic }}$ is taken as 1 scale unit in the present analysis on Thuwal area.

3. $\rho_{\text {mac. }}$ This is used in the cluster fusion after multiplication by the maximum horizontal radius of confidence of all the clusters. It calculates the maximum distance which allows for two clusters to be fused. This is taken as 1 .

4. $\rho_{z}$, a scaling factor to convert the depth to circles with radii proportional to the depths in the $2 \mathrm{D}$ graph representations. This is taken as equal to 0.5 units.

5. The inclination and declination of the study area are $30^{\circ}$ and $2^{\circ}$, respectively, obtained from the IGRF study. We applied the deconvolution technique using second advanced cluster stage.

The threshold value is taken as $\tau=0.0002$. The results are shown in Fig. 11 to 14 . Figure 11 shows the horizontal gradients, Tx, and Ty, and the vertical gradient, Tz, that have been calculated for this analysis. Figure 12 shows the analytic signal in the 3-dimensional space where the light colors represent the possible peaks in the area. These peaks are attained exactly over the magnetic contacts or dykes. Figures $13(\mathrm{a} \& \mathrm{~b})$ show the source horizontal projections and the clusters indices of the solutions, respectively. Figure 13(c). shows the clusters horizontal projections together with a primary statistics of the solution where a fusion of clusters algorithm was implemented consisting of classifying in the same cluster, all the points of the clusters whose horizontal centre of 
gravity distances are less than $\rho_{\mathrm{mac}} r^{\max }$, where $\rho_{\text {mac }}$ is an empirical factor, and $r^{\max }=\max \left(\sqrt{\mathrm{c}_{\mathrm{x}}^{2}+c_{y}^{2}}\right)$ is the maximum horizontal radius of confidence interval of all the clusters, and $\mathrm{c}_{\mathrm{x}}$ and $\mathrm{c}_{\mathrm{y}}$ are the half confidence intervals of the horizontal coordinates of each cluster's gravity centre. Figure 13(d) is the cluster indices after the second cluster stage and the first grouping. The confidence intervals for the horizontal coordinates are depicted by an ellipse with a centre, defined by their average values and axes, equal to the confidence intervals in the respective directions. The main axis of the ellipse indicates the prevailing direction from which the solutions in a cluster were collected. The total number of the obtained cluster solutions is 275 for this advanced stage.

Comparing Fig. 13(c \& d) for cluster no. 2, for example, one can conclude that the east-west directions are the dominant direction from which the solution is obtained. The average depth to the magnetic sources is $0.049 \mathrm{~km}$ with a confidence interval 0.115 , and the average corresponding structural indices is 0.436 , having a confidence interval as $N=0.697$ (Table 1) .

Figure $14(\mathrm{a} \& \mathrm{~b})$ show a 3D block diagram for the structural indices and source depths, respectively. The maximum depth obtained for the magnetic sources is about $3 \mathrm{~km}$ whereas the shallowest magnetic source is about $50 \mathrm{~m}$. The Structural indices range between 0 and 3. According to Reid (2003) and from the analysis of our data in Thuwal area (Table 1), the average structural index is found to be 0.624 , indicating a shallow contact-like structures close to thin dike structures ( SI between 0 and 1). The present analysis can group the results in five main groups (G1 to G5) as shown in (Table 2). Group (G1) includes clusters 4,6, and 10 , trending NE-SW which can be correlated with the major thrust master faults and dipping in the NW direction. It has an average SI of about 0.473 and average depth of about $0.067 \mathrm{~km}$, indicating a shallow contact or dike like structure. Group (G2) is represented by clusters 2, 3, and 4 which have an average SI of about 0.581 and average depth of about $0.089 \mathrm{~km}$, indicating also a shallow contact or dike like structure trending NW-SE, which is the trend of the Red Sea. Group (G3), containing clusters 2 and 8, is trending in the NE-SW direction. Group (G4), including clusters 5 and 8 , has an average SI of about 0.678 and average depth of about $0.108 \mathrm{~km}$, indicating also a shallow contact or 

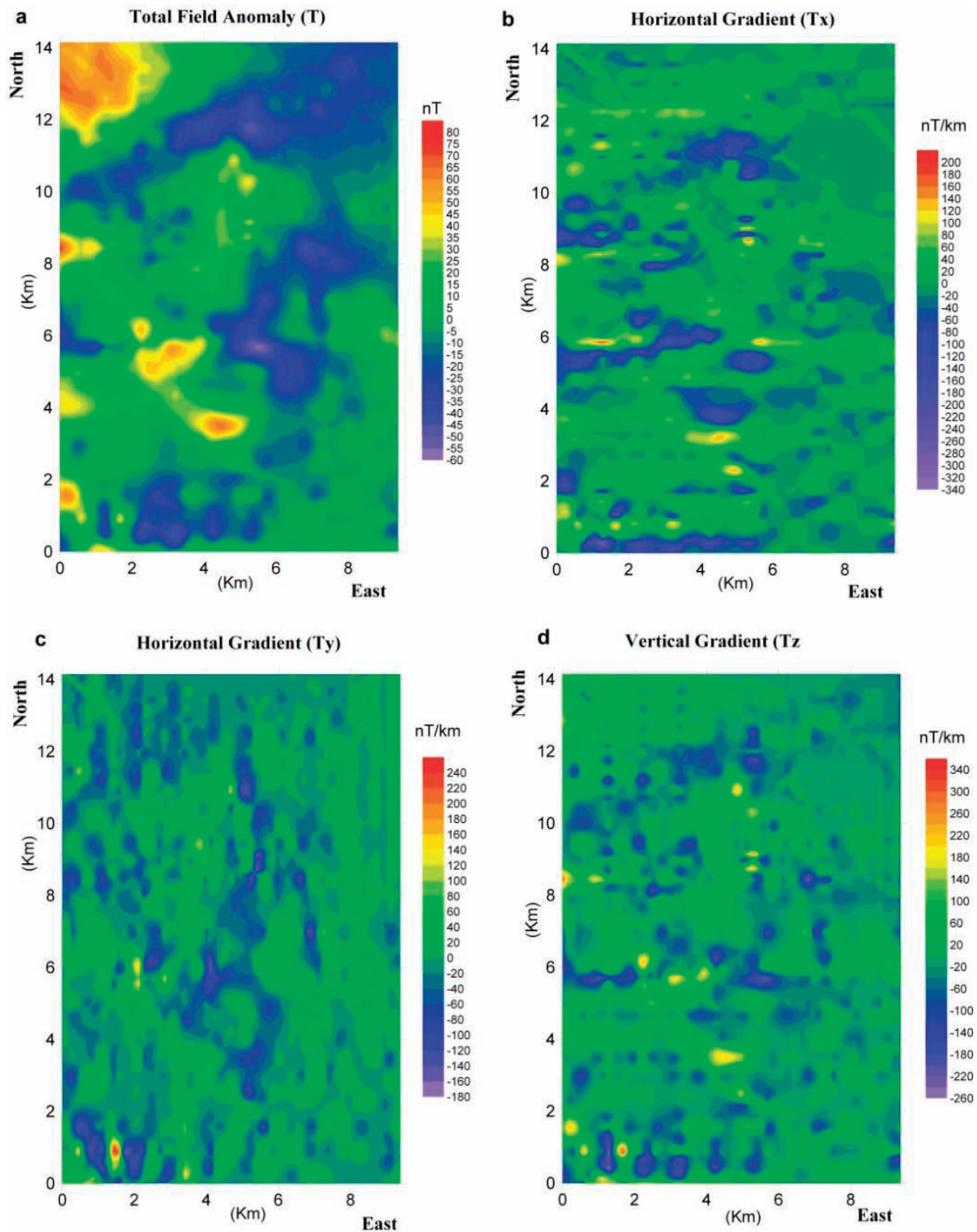

Fig. 11: a) Total field intensity map of Thuwal area, b) Horizontal gradient of the total intensity map in the east direction $(T x)$, c) Horizontal gradient in the North direction (Ty), and Vertical derivative ( Tz). 


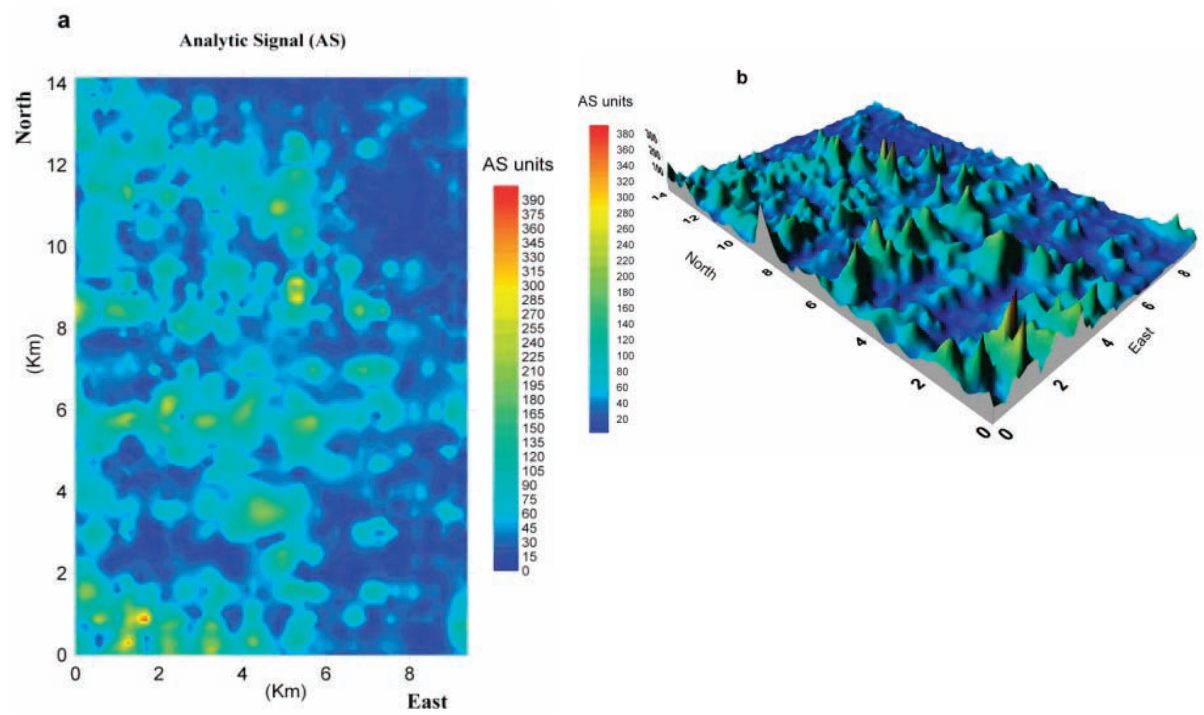

Fig. 12. Analytic Signal (AS) for Thuwal area. a) Map view, and b) Block view.

Table 1. Statistical analysis of clusters of the second stage.

\begin{tabular}{|c|c|c|c|c|c|c|c|c|c|}
\hline $\begin{array}{l}\text { Cluster } \\
\text { index }\end{array}$ & Num-Pi & Xavr & Xcon & Yavr & Ycon & Zavr & Zcon & $\begin{array}{c}\text { Navr } \\
(\mathbf{0 . 6 2 4 3})\end{array}$ & Ncon \\
\hline 1 & 21 & 1.14 & 1.099 & 1.077 & 1.111 & 0.153 & 0.182 & 0.873 & 1.435 \\
\hline 2 & 42 & 5.89 & 0.513 & 2.389 & 3.322 & 0.094 & 0.115 & 0.456 & 0.697 \\
\hline 3 & 11 & 11.56 & 0.196 & 0.850 & 0.666 & 0.095 & 0.164 & 0.625 & 1.216 \\
\hline 4 & 27 & 8.85 & 1.228 & 2.229 & 1.589 & 0.078 & 0.131 & 0.663 & 1.433 \\
\hline 5 & 65 & 1.44 & 1.648 & 5.534 & 2.876 & 0.126 & 0.174 & 0.653 & 1.265 \\
\hline 6 & 7 & 11.48 & 1.636 & 4.609 & 0.875 & 0.060 & 0.100 & 0.234 & 0.578 \\
\hline 7 & 23 & 9.001 & 0.303 & 5.249 & 0.189 & 0.080 & 0.097 & 0.853 & 0.973 \\
\hline 8 & 12 & 3.304 & 0.659 & 7.0755 & 0.674 & 0.089 & 0.152 & 0.703 & 1.212 \\
\hline 9 & 48 & 7.620 & 2.236 & 6.957 & 0.672 & 0.095 & 0.137 & 0.658 & 1.175 \\
\hline 10 & 19 & 12.913 & 0.858 & 7.040 & 1.172 & 0.063 & 0.070 & 0.521 & 0.827 \\
\hline \multicolumn{5}{|c|}{$\begin{array}{l}\text { Navr: average estimated structural indices for each } \\
\text { cluster }\end{array}$} & \multicolumn{5}{|c|}{ Num-Pi: Number of points } \\
\hline \multicolumn{5}{|c|}{$\begin{array}{l}\text { Ncon: confidence interval for each structural indices } \\
\mathrm{N}\end{array}$} & \multicolumn{5}{|c|}{ Xavr: average $X$ value } \\
\hline \multicolumn{5}{|c|}{ Zcon: confidence interval for variable $\mathrm{Z}$} & \multicolumn{5}{|c|}{ Xcon: confidence interval for variable $\mathrm{X}$} \\
\hline \multicolumn{5}{|c|}{ Zavr: average $Z$ value } & \multicolumn{5}{|c|}{ Yavr: average Y value } \\
\hline & & & & & \multicolumn{5}{|c|}{ Ycon: confidence interval for variable $Y$} \\
\hline
\end{tabular}


a

Sources horizontal projections-

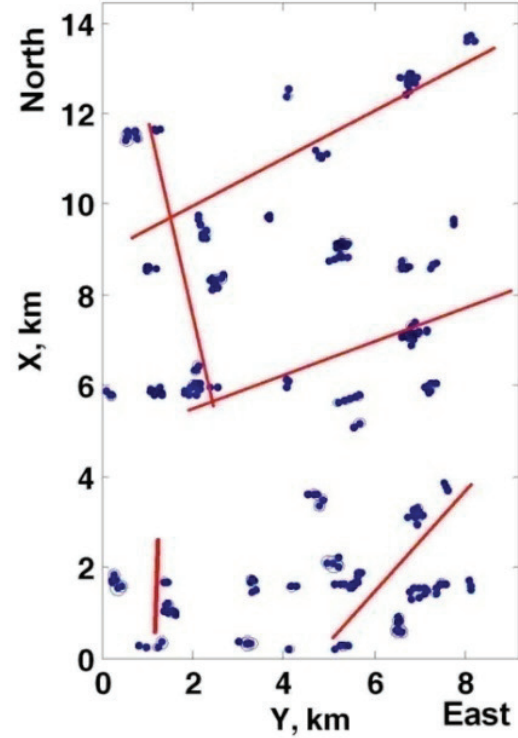

C

Clusters horizontal projections

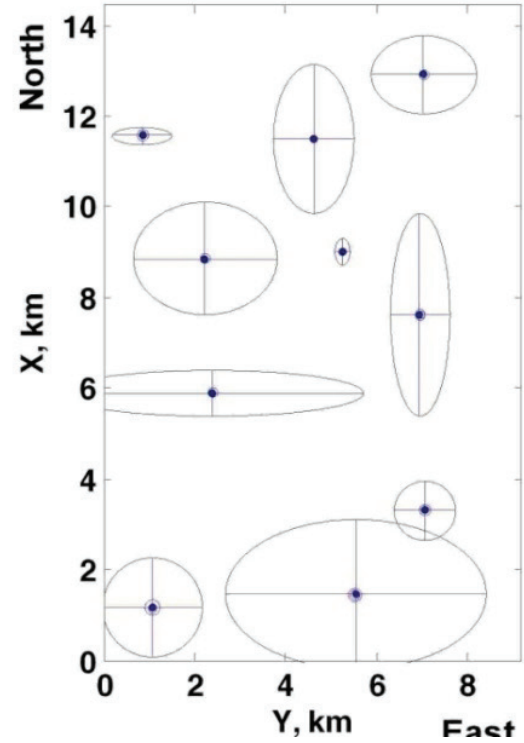

b

Clusters indices of the solutions-
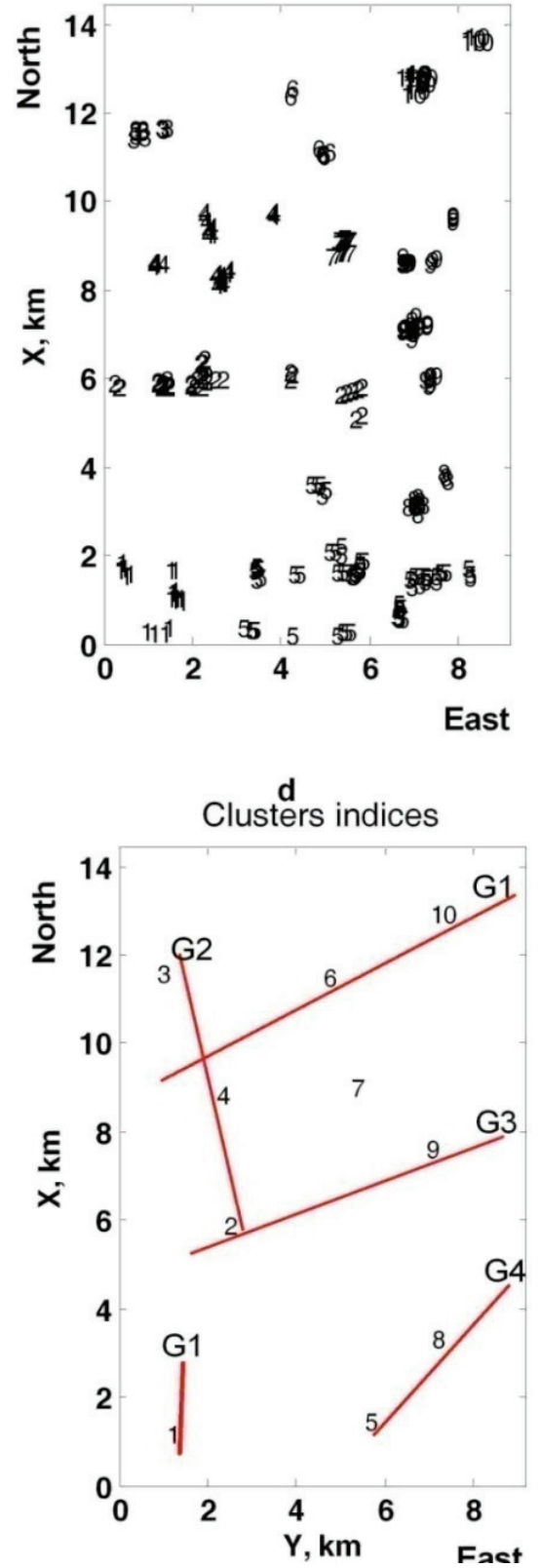

Fig. 13. Statistical and surface distribution of the solutions from 3D Euler deconvolution. a) Source horizontal projections, b) Clusters indices of the solutions, c) Clusters horizontal projections, and d) Cluster indices. 

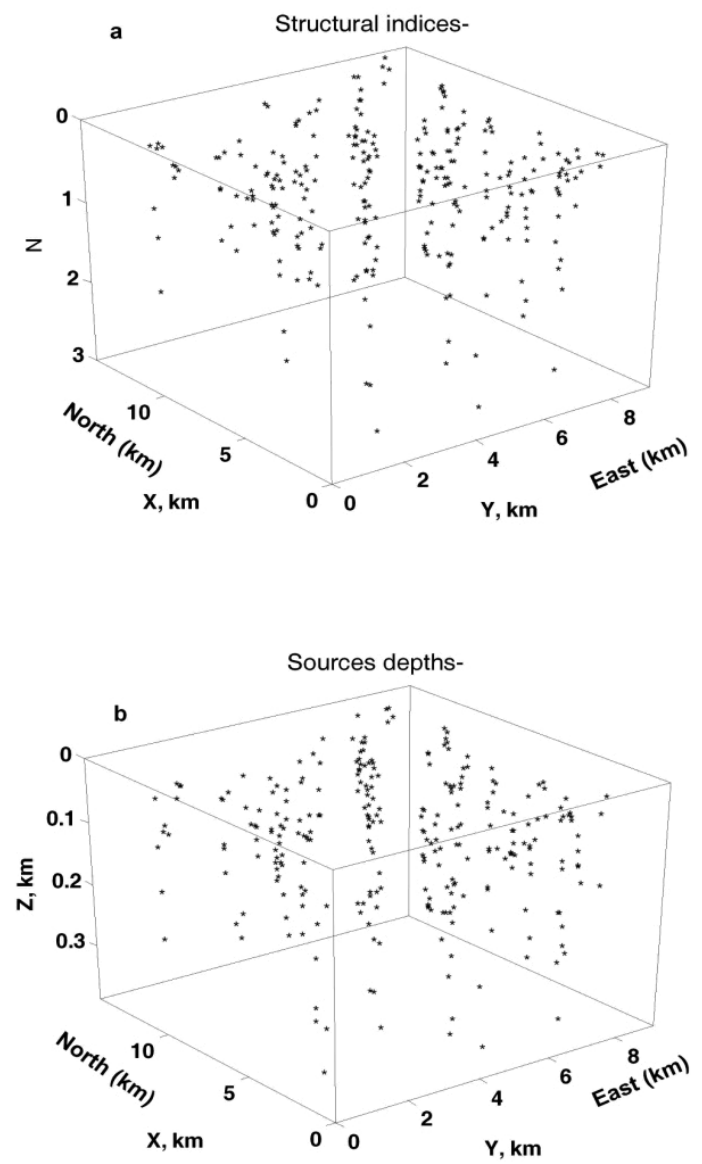

Fig. 14. Source indices (a), and Source depths (b).

Table 2. Average depths and structural indices for different groups.

\begin{tabular}{|c|c|c|c|}
\hline Group & Zavr & Navr & Cluster index \\
\hline G1 & 0.067 & 0.473 & $4,6,10$ \\
\hline G2 & 0.089 & 0.581 & $2,4,3$ \\
\hline G3 & 0.094 & 0.557 & 2,9 \\
\hline G4 & 0.108 & 0.678 & 5,8 \\
\hline G5 & 0.153 & 0.873 & 1 \\
\hline
\end{tabular}


dike like structure and trending NE-SW. Finally, group (G5), including cluster 1 , is trending N-S or NNW-SSE. The latter group has an average SI of about 0.87 and average depth of about $0.153 \mathrm{~km}$. Most depths obtained from this technique are shallower than the other depths obtained by the other techniques. This can be explained based on the fact that the method is very sensitive because its core algorithm is based on gradients and hence any magnetic source elements along shear zones or fault planes may extend from basement to the surface, which can affect the results and give shallower massive sources than expected.

\section{Discussion and Conclusion}

A number of points should be considered for ground-magnetic anomalies observed in Thuwal area:

First, we can rule out basement rocks as potential magnetic sources because the extensive susceptibility analysis from different rock samples and in situ measurements in the area showed that the sedimentary cover has minimum effect on the magnetic signature and the susceptibility map has weak correlation with the observed TMI map, except, some possible intra sedimentary basaltic materials.

Second, many of the observed surface faults (as indicated from the geology) have a critical role in surface drainage pattern. Therefore, the interpreted subsurface structures could be affecting the subsurface drainage system.

Third, the analytic signal analysis (2D and 3D) and derivative maps show several trends that are crossing the area. These trends (possibly related to faults or contacts) are extended to the eastern basement outcrop. Some of these faults/contacts are considered as major faults, which evidently have an effect on water distribution in the Wadi. Among the measured trends are the following signatures:

1. NE-SW: these are trust faults and shear zones restricted to the basement. Among these faults is F1 (Fig. 4), that extends from the NE of the study area to the extreme NW part, north of Harrat Thuwal. The dip of this thrust is in the NW direction based on the available geological and magnetic information. 
2. Faults related to the Red Sea tectonics as follow:

a) The rift shoulder master faults: These bounds the basement exposures in the eastern part of the map (see geologic map), which has a $\mathrm{N}-\mathrm{S}$ trend through to the west. The trend of these faults deviates to the NW-SE in the northern part of the study area. This system of faults is represented by faults F10, F11, F12 on (Fig. 4).

b) NW-SE normal faults: These faults control the distribution of the Harrat Thuwal in the NW and south of the mapped area. These faults, generally, are trending NW-SE, which is the trend of the Red Sea, and through to the NE and SW, where the Harrat is elevated as horsts. Among this trend is F2 on (Fig. 4).

c) NNE-SSW normal faults: These faults are observed at the western part of the study areas as major faults where these faults disrupt the Harrat and the refal limestone distributed in the area. e.g. F3 on (Fig. 4).

Fourth, magnetic minerals may occur along the faults or magnetic contacts, extending to the alluvial section, which can be referred to as secondary mineralization such as calcite veins. These calcite veins include opaque minerals which may explain that some of the estimated depths seem to be shallow. Finally, The analysis using the Euler deconvolution with $\mathrm{N}=1$ reveals distinctive patterns of subsurface dikes, prevailing in the area and cutting to the basement, which may be raised to dike swarms trending NW-SE and NNW-SSE.

\section{Acknowledgments}

The authors would like to thank the King Abduaziz City for Science and Technology (KACST) for supporting this work. This work is granted by KACST No. AT-26-82. Also, many thanks go to the two anonymous reviewers for their comments and suggestions which highly improved the original manuscript.

\section{References}

Al-Garni, M.A. (2007) Aeromagnetic Data Analysis of The Southeastern Quarter of Al-Muwayh Quadrangle, Saudi Arabia (accepted for publication in the Journal of Applied Geophysics, Egypt), 6(2): 487-512.

Al-Garni, M.A., El-Behiry, M.G, Gobashy, M.M., Hassanein, H.I. and El-Kaliouby, H.M. (2009) Geophysical Studies to Assess Groundwater Potentiality and Quality at Wadi Thuwal Area, North of Jedda, KSA: King Abdulaziz City for Science and Technology, project No. At-26-82, p: 394. 
Atchuta Rao, D., Ram Babu, H.V. and Sanker Narayan, P.V. (1981) Interpretation of magnetic anomalies due to dikes: The complex gradient method, Geophysics, 46: 15721578.

Carmichael, R.S. (1982) Magnetic Properties of Minerals and Rocks: CRC.

Cordell, L. and Grauch, V.J.S. (1985) Mapping basement magnetization zones from aeromagnetic data in the San Juan basin, New Mexico, in Hinze, W.J., Ed., The utility of regional gravity and magnetic anomaly maps: Soc. Expl. Geophys., 181-197.

Gerovska, D. and Bravo, M.J.A. (2003) Automatic interpretation of magnetic data based on Euler deconvolution with un-prescribed structural index: Computers \& Geosciences, 29: 949-960.

Gobashy, M. (2006) Analysis of Aeromagnetic measurements from the southern part of Al Hissu quadrangle, Saudi Arabia using Euler deconvolution with unprescriped structural index. Accepted for publication in the Journal of Petroleum and mining Engineering (JPME), Suez Canal University.

Gobashy M.M. and Al-Garni, M.A. (2008) High Resolution Ground Magnetic Survey (HRGM) for Determining the Optimum location of Subsurface Dam in Wadi No'man, Makkah al Mukarammah, KSA: Journal of King Abdulaziz University, JKAU: Earth Sci., 19: 57-83.

Hansen, R.O., Pawlowski, R.S. and Wang, X. (1987) Joint use of analytic signal and amplitude of horizontal gradient maxima for three-dimensional gravity data interpretation: $57^{\text {th }}$ Ann. Internat. Mtg., Soc. Expl. Geophys., Expanded Abstracts, 100-102.

Hartman, R.R., Teskey, D.J. and Friedberg, J.L. (1971) A system for rapid digital aeromagnetic interpretation: Geophysics, 36: 891-918.

Hsu, S.K., Sibuet, J.C. and Shyu, C.T. (1996) High-resolution detection of geologic boundaries from potential-field anomalies: An enhanced analytic signal technique: Geophysics, 61: 373-386.

Jain, S. (1976) An automatic method of direct interpretation of magnetic profiles: Geophysics, 41: $531-541$.

Lilliefor, H.W. (1967) On the Kolmogorov-Smirnov test for normality with mean and variance unknown: JASA, 62: 399-402.

Nabighian, M.N. (1972) The analytic signal of two-dimensional magnetic bodies with polygonal cross-section: its properties and use for automated anomaly interpretation: Geophysics, 37: 507-517.

(1974) Additional comments on the analytic signal of two-dimensional magnetic bodies with polygonal cross-section: Geophysics, 39: 85-92.

(1984) Toward a three-dimensional automatic interpretation of potential field data via generalized Hilbert transform: Fundamental relations: Geophysics, 49: 780-786.

Naudy, H. (1971) Automatic determination of depth on aeromagnetic profiles: Geophysics, 36: 717-722.

Ramsay, C.R. (1986) Geologic map of the Rabigh Quadrangle, Geoscience Map GM-84C, Sheet 22D, Kingdome of Saudi Arabia. Ministry of petroleum and mineral resources, Saudi Arabia.

Reid, A.B., Allsop, J.M., Granser, H., Millet, A.J. and Somerton, I.W. (1990) Magnetic Interpretation in the three dimensions using Euler deconcolution: Geophysics, 55: 80-91.

Roest, W.R., Verhoef, J. and Pilkington, M. (1992) Magnetic interpretation using the 3-D analytic signal: Geophysics, 57: 116-125 
Stavrev, P.Y. (1997) Euler deconvolution using differential similarity transformations of gravity or magnetic anomalies: Geophys. Prosp., 45: 207-246.

Stavrev, P., Gerovska D. and Araúzo-Bravo, M.J. (2003) Euler deconvolution of magnetic anomalies over the basaltic bodies in northern Bulgaria: Annual, 46: part 2, Geology and Geophysics, Sofia, 403-407.

Thompson, D.T. (1982) EULDPH-A new technique for making computer-assisted depth estimates from magnetic data: Geophysics, 47: 31-37.

Vacquier, V., Steenland, N.C., Handerson, R.G. and Zietz, I. (1951) Interpretation of aeromagnetic maps: Geol. Soc. Am: Mem. 47. 
الدر اسة المغنطيسية الأرضية لاستباط التر اكيب تحت السطحية المؤثزة على وداي ثول - المملكة العربية السعودية

منصور عبد الله القرني ، ومحمد مصطفى غباشي قسم الجبوفيزياء - كلية علوم الأرض - جامعة الملك عبد العزيز جـدة - المدلكة العربية السعودية الإناه

المستخلص. تم إجر اء مسح مغنطيسي أرضي علــى منطقـــة وادي

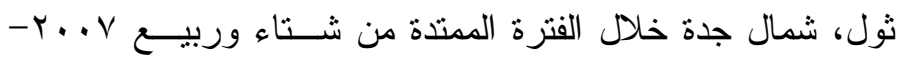

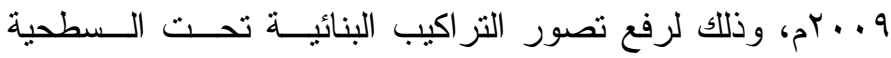

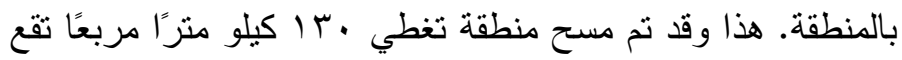

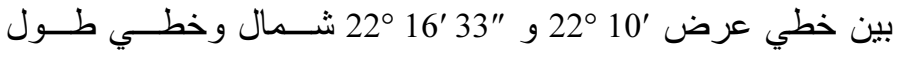

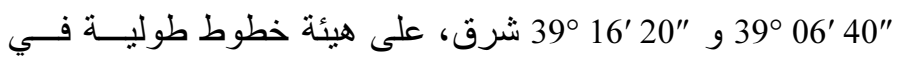
اتجاهات شرق - غرب و شمال - جنوب. وتم إجراء التصحيحات

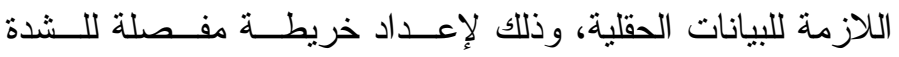

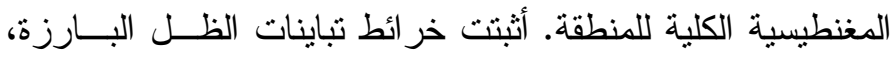
وجود اتجاهات بنائية وشاذات ذات خصائص مميزة بالمنطقة. وتم

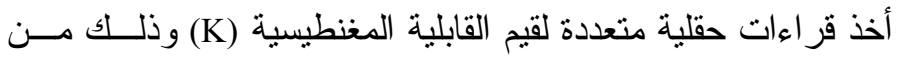

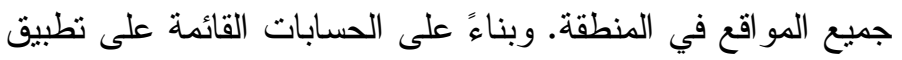

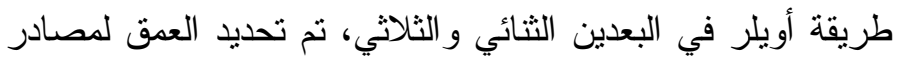
الثاذة المغنطيسية بالمنطقة. وتوصلت الدراسة إلى كثف العديد من

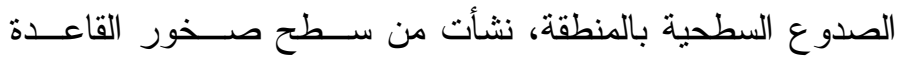

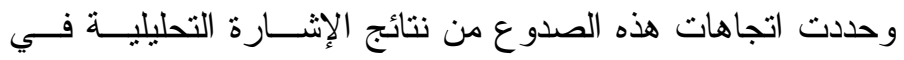

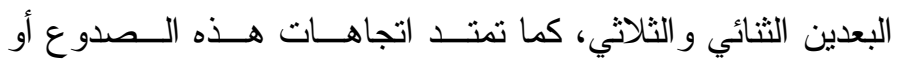
الالتصاقات الصخرية إلى شرق منطقة الدراسة، وربما تصل إلـى في إنى 


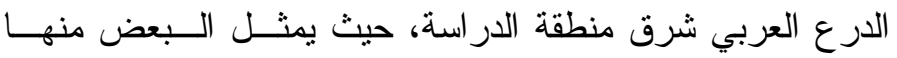

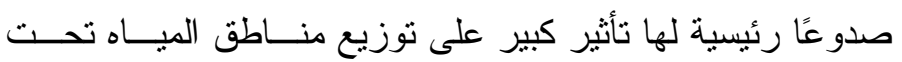
السطحية بالو ادي محل الدر اسة. وبصفة عامة تأخذ هذه الـصدوع اتجاهات شمال شرق - جنوب غرب، وشــــال جنــوب، وشــــال غرب - جنوب شرق، وشمال شمال شرق - جنوب جنوب غرب.

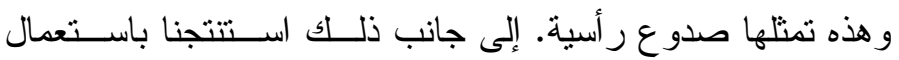
طريقة تحليل أويلر ثالثية الأبعاد وجود بعض الجدد بالمنطقة. ورذه ربما تكون امتذادًا لما يسمى بـــــد الجدد ذات الاتجـــاه شــمال غرب - جنوب شرق، شمال شمال غرب - جنوب جنوب شــرق المعروف بالمنطقة. 